\title{
A NEONATAL TETANUS DEATH: AN OPPORTUNITY LOST
}

\author{
Jenita Baruah¹, Tulika G. Mahanta², Abhijit Dutta ${ }^{3}$, Arpita Gogoi .
}

1. Assistant Professor, Department of Community Medicine, Assam Medical College, Dibrugarh.

2. Associate Professor, Department of Community Medicine, Assam Medical College, Dibrugarh.

3. Registrar, Department of Paediatrics, Assam Medical College, Dibrugarh.

4. Assistant Professor, Department of Paediatrics, Assam Medical College, Dibrugarh.

\section{CORRESPONDING AUTHOR}

\section{Dr. Jenita Baruah,}

DQ: 12, G-Lane,

Assam Medical College Campus,

Dibrugarh: 786002, Assam.

Email- jenita_19baruah@rediffmail.com

\section{HOW TO CITE THIS ARTICLE:}

Jenita Baruah, Tulika G. Mahanta, Abhijit Dutta, Arpita Gogoi. "A Neonatal Tetanus Death: An Opportunity Lost". Journal of Evolution of Medical and Dental Sciences 2013; Vol2, Issue 25, June 24; Page: 4528-4530.

\begin{abstract}
Neonatal tetanus is a fatal disease of newborn acquired when the spores of the bacterium Clostridium Tetani infect a wound or the umbilical stump. Neonatal tetanus can be prevented by immunization of pregnant women with two doses of tetanus toxoid, and clean delivery practices. A neonate presented to a tertiary care hospital with neonatal tetanus. The baby was born to an unimmunized mother, with no aseptic measures taken during delivery and application of goat excreta and mustard oil in umbilical stump but residing within reach of health care services. Government of Assam, under National Rural Health Mission and Janani Suraksha Yojana has taken all efforts to ensure complete immunization of pregnant mothers and to increase institutional delivery. Inspite of all efforts, failure of the health care services to reach the parents of the present case shows that much remains to be done to prevent neonatal tetanus.
\end{abstract}

KEY WORDS: Neonatal tetanus, clean delivery practice, antenatal immunization

INTRODUCTION: 'Neonatal Tetanus' is caused by the action of a potent neurotoxin produced when the spores of the bacterium Clostridium Tetani present in the soil infect the umbilical stump following unclean deliveries practices. Tetanus constitutes a considerable public health problem. ${ }^{1}$ and is mostly fatal in newborn babies. It is usually seen in rural areas where deliveries are conducted at home without adequate sterile procedures. ${ }^{2}$ It can be prevented by immunization of pregnant women with two doses of tetanus toxoid (TT) and promoting clean delivery practices. ${ }^{3}$

Government of Assam, under National Rural Health Mission (NRHM) and Janani Suraksha Yojana 4 (JSY) has organized special drives to ensure total immunization coverage of pregnant women, and to increase institutional delivery to ensure clean delivery care. ${ }^{5}$ Here we present a case of neonatal tetanus occurring in a baby born at home under unsterile condition to a mother with no TT immunization and without the assistance of a skilled birth attendant but residing within the reach of health care system. 
CASE HISTORY: A 12 day old male baby weighing $3 \mathrm{~kg}$ presented to the pediatrics OPD of a tertiary care hospital with complaints of refusal to take feeds, inability to open his mouth, repeated jerky movement of the body and persistent facial grimace since tenth day of his birth. The presentation to the hospital was delayed by two days due to delay during referral process from primary health centre.

History revealed that the patient was delivered at home with assistance of an untrained dai. The delivery was conducted on the katcha floor over which a jute sac was laid and on top a blanket was laid indicating no aseptic care was taken during delivery, although a new blade and thread was used to cut and tie the umbilical cord. The baby was bathed immediately after delivery and goat excreta mixed with mustard oil was applied to the umbilical cord stump. This practice was carried out daily after bathing the baby till the $10^{\text {th }}$ day. Twenty year old mother was a primigravida with no history of TT immunization during the entire period of pregnancy. She and her husband were not aware of its importance. She was not visited by any primary health care worker during her pregnancy. Both the parents were illiterate, daily wage earner with monthly family income of approximately 2000 rupees and were residing within reach of the primary health care services.

On examination the newborn was found to be febrile, with elevated respiratory and heart rate. Umbilical cord stump was dry with no sign of inflammation. Patient had severe spasms involving whole body. He had opisthotonic posturing with arching of the back. Pupils were bilaterally normal and reactive, jerks were brisk and further examination was difficult with continued spasm. Blood and CSF were collected under Diazepam cover and were sent for investigation. No organism was isolated on blood culture. Blood examination findings were as follows - Haemoglobin 12Gram/dl, Urea $50 \mathrm{mg} / \mathrm{dl}$, creatinine $1 \mathrm{mg} / \mathrm{dl}$, and calcium $10.1 \mathrm{mg} / \mathrm{dl}$, CSF showed protein $40 \mathrm{mg} / \mathrm{dl}$, Sugar $50 \mathrm{mg} / \mathrm{dl}$ and 4 cells/hpf all being lymphocytes

The newborn was immediately shifted to the paediatric intensive care unit and was started on intravenous fluid, anticonvulsants, oxygen and anti tetanus Immunoglobulin. The condition did not improve and patient expired on the $5^{\text {th }}$ day of admission.

DISCUSSION: Neonatal tetanus is an acute disease presenting initially with loss of ability to suck, followed by generalized rigidity and painful muscle spasms as the disease progresses. The disease is caused by tetanus toxin produced by Clostridium Tetani and is diagnosed entirely on the basis of the clinical findings. ${ }^{6}$ Present case was admitted to the hospital with a history of inability to suck followed by rigidity and jerky movements of limbs. Hence the present case was diagnosed as a case of Neonatal tetanus.

The commonest port of entry for the tetanus spores is the unhealed umbilical cord and application of a contaminated material on the umbilical stump increases the chance of the disease. ${ }^{7}$ Usually Clostridium tetani infection in the wound does not produce sign of any inflammation ${ }^{3}$. The present case had a history of application of goat excreta mixed with mustard oil on the umbilical stump and on examination the stump had no sign of inflammation. The probable port of entry of the tetanus spores in the present case was the umbilical cord with application of goat excreta and mustard oil being the provocative factor.

Maternal immunization is the best prevention for Neonatal Tetanus. Two doses of tetanus toxoid produces sufficient Immunoglobulin $G$ in mother to prevent neonatal tetanus in the 


\section{CASE REPORT}

newborn. ${ }^{3}$ The patient in the present case was born to an unimmunized mother hence was vulnerable to the disease.

Quality Antenatal care, including TT, followed by skilled obstetric care at birth has potential to reduce $51-70 \%$ neonatal mortality rate. JSY had a significant effect on increasing in-facility births hence clean delivery care. ${ }^{8}$ Present case had neither antenatal immunization by two doses of Tetanus toxoid nor had clean delivery care under supervision of trained birth attendant. The mother was not visited by any health care worker which is an important component of NRHM in Assam.

In spite of all efforts, failure of the health care services to reach the parents of the present case during pregnancy, delivery or during neonatal period shows that opportunities to prevent neonatal tetanus were lost on three occasions. Present case is an eye opener of the lacunae in the effort.

\section{REFERENCES:}

1. WHO, Weekly epidemiological record No. 20, 2006, 81, 197-208 available from: http://www.who.int/wer. [last accessed on 6th June 2012]

2. WHO publication, available from: www.who.int/immunization/topics/tetanus/en/ . [last accessed on 6th June 2012]

3. Elias Abrutyn. Tetanus. Fauci, braunwald, Kasper, Hauser, Longo Jameson, and Loscalzo , editors, Harrison's Internal Medicine, 17th ed New York, St. Louis, San Francisco, Auckland, Bogota, Caracas, Lisbon, London, Madrid, Mexico city, Milan, Montreal, New Delhi, San Juan Singapore, Sydney, Tokyo, Toronto , Mc Graw Hill, Health profession division, 2008 Page 898-900.

4. Kishor J. Janani Suraksha Yojana. National rural Health mission, Chapter 6, National Health Programmes of India, National policies and legislations related to health, 9th ed, New Delhi, Century publication 2011, 88-109.

5. State Programme Implementation Plan 2009-10, State Health Mission. National Rural Health Mission Government Of Assam accessed on assam_spip_09_10_text_pip_2009_10assam.pdf [last accessed on 6th June 2012]

6. Department of Health Family Welfare. Immunization handbook for Medical officers (revised edition 2009) , New Delhi, Ministry of health and Family welfare Govt of India, New Delhi pp 161, available from www.mohfw.nic.in [last accessed on 6th June 2012]

7. Hannah Blencowe, Joy Lawn, Jos Vandelaer, Martha Roper and Simon Cousens. Clean birth and postnatal care practices to reduce neonatal deaths from sepsis and tetanus: a systematic review and Delphi estimation of mortality effect 2010. International Journal of Epidemiology 2010; 39:i102-9.

8. Lim.S.S,Dandona L,Hoisington JA et al. India's Janani Suraksha Yojana, a conditional cash transfer programme to increase births in health facilities: an impact evaluation. The Lancet 2010;375:2009-23 